\title{
Comparison of the Effect of Sole Reflexology Massage and Stretching Exercises on Pain Severity of Patients with Rheumatoid Arthritis
}

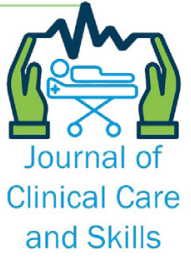

\section{ARTICLE INFO}

\section{Article Type}

Original Research

\section{Authors}

Sadeghi M. ${ }^{1} M S C$,

Zabolipour S. ${ }^{2} M S c$,

Afrasiabifar A. ${ }^{2} P h D$

Najafi Doulatabad Sh. ${ }^{* 2}$ MsC
How to cite this article

Sadeghi M,ZabolipourS,Afrasiabifar A, NajafiDoulatabadSh.Comparison of the Effect of Sole Reflexology Massage and Stretching Exercises on Pain Severity of Patients with Rheumatoid Arthritis. Journal of Clinical Care and Skills. 2020;1(3):103 107.

\section{A B S T R A C T}

Aims Rheumatoid arthritis is the most common autoimmune disease of chronic inflammation and pain is one of the most prevalent complaints of these patients. The aim of this study was to compare the effect of sole reflexology massage and stretching exercises on pain severity of patients with rheumatoid arthritis.

Materials \& Methods This clinical trial study was conducted among 75 patients with rheumatoid arthritis referred to the Shahid Mofatteh Clinic in Yasuj, Iran in 2017-18. Subjects were selected by purposive sampling method and divided into three groups including sole reflexology massage, stretching exercises and control groups by random block allocation ( $N=25$ in each group). The interventions were carried out for one month including 30-minute sessions three times a week. Pain severity of patients was evaluated before interventions and 10 minutes after the last intervention session using Standardized visual analogue scale (VAS). Data were analyzed by SPSS 21 software using Chi-square test, one-way ANOVA and Tukey post hoc tests.

Findings Before interventions, the mean score of pain of patients among sole reflexology massage, stretching exercises and control groups had no significant difference $(p=0.1)$. After interventions, a significant difference was observed in the pain severity of patients of three groups ( $\mathrm{p}=0.001$ ) that this difference was related to the stretching exercises group compared to the sole reflexology massage and control groups.

Conclusion Stretching exercises reduce the pain severity of patients with rheumatoid arthritis, but sole reflexology massage does not improve or reduce the pain of these patients. Keywords Reflexology Massage; Stretching Exercises; Pain; Rheumatoid Arthritis
${ }^{1}$ Student Research Center, Yasuj University of Medical Sciences, Yasuj, Iran ${ }^{2}$ Medical Surgical Nursing Department, School of Nursing, Yasuj University of Medical Sciences, Yasuj, Iran

\section{*Correspondence}

Address: Nursing Faculty, Yasuj University of Medical Sciences, Shahid Jalil Street, Yasuj, Iran. Postal Code: 7591994799.

Phone: +98 (74) 33234115

Fax: +98 (74) 33234115

shahlaiss@yahoo.com

\section{Article History}

Received: December 08, 2019

Accepted: December 28, 2019

ePublished: September 21, 2020

\section{I T A T I O N L I N K S}

[1] Utility of animal models for identification of potential ... [2] Harrisos's principles of internal medicine: rheumatology \& ... [3] Clinical skills: evidence-based nursing care of people ... [4] Chronic widespread pain in thespectrum of ... [5] Cognitive, behavioral and physiological reactivity ... [6] Patient barriers to pain management may contribute ... [7] Pain and quality of life among older people with rheumatoid ... [8] Patients' perceptions of health-related quality of life ... [9] Positive affect as a factor of resilience in the pain ... [10] Medical surgical ... [11] Effects of arthritis exercise programs on functional ... [12] The effect of symptoms and signs of disease on the ... [13] Female patients tend to alter their diet following ... [14] The effects of foot reflexology on fatigue and insomnia ... [15] Improving the management of ... [16] Study of the effects of massage therapy on the ... [17] T229 Reducing of pain in patients with fibromyalgia ... [18] Hand arthritis pain is reduced by massage ... [19] Pain perception after isometric exercise in women ... [20] Exercise therapy for ... [21] Comparison of impacts of friction massage, stretching exercises ... [22] Massage impairs postexercise muscle blood ... [23] Comparison of manual lymph drainage therapy and ... [24] Strengthening and stretching for Rheumatoid Arthritis of the ... [25] Effects of strengthening and aerobic exercises ... [26] Dynamic exercise therapy in rheumatoid arthritis ... [27] The effect of aerobic exercise (stretching exercise) on the fatigue... 


\section{Introduction}

Rheumatoid arthritis causes chronic inflammation and pain in the joints, usually affecting the joints symmetrically [1]. Its prevalence is about $1 \%$ worldwide and is more prevalent in women, with the ratio of women to men being about 3 to $1{ }^{[2]}$. Arthritis symptoms present as pain, swelling, and limited range of motion of the joints [3].

Chronic pain as a common and unpredictable symptom is not only an unpleasant physical experience but also due to the severity and duration of pain is a stressor in these patients. In addition, it affects patients' health, performance, as well as their quality of life, and they often have negative assessments and maladaptive behaviors about their ability to control pain [4-9].

In addition to physical consequences, pain can also result in psychological and emotional problems, such as changes in role-playing, impairment of one's mental image and an impaired sense of selfconfidence, which must be addressed [10]. Despite the effectiveness of drug therapy, the pain has remained as a clinical problem [11]. According to the available evidence, half of the rheumatoid arthritis patients reported severe pain [12]. These patients often try to use alternative or complementary therapies because of the prolonged treatment period and the numerous side effects of drug therapy [13]. Although drug therapy is the most important available method to nurses to relieve pain, however, due to side effects and differences in patients' response to painkillers and opiates, it is important to use non-pharmacological approaches to reduce and manage pain in addition to drug therapy [14-16]. In addition, non-pharmacological methods are usually cheaper and applicable to patients everywhere.

Accordingly, due to the importance of pain reduction in order to follow the preferred method, this study aimed at comparing the effect of sole reflexology massage and stretching exercises on pain severity in patients with rheumatoid arthritis.

\section{Materials and Methods}

This clinical trial study was conducted on the patients with rheumatoid arthritis referred to the Shahid Mofatteh Clinic in Yasuj, Iran in 2017-18. Study samples included 75 patients with rheumatoid arthritis who met the inclusion criteria, including the informed consent to participate in the study, a definitive diagnosis of rheumatoid arthritis by a rheumatologist, at least passing one year after diagnosis, the age of over 18 years, no ulcers, fractures, and sensory-motor disorders in lower extremities, obtaining a score of at least 4 based on the Visual Analogue Scale (VAS), no use of narcotic analgesics and a permission to participate in the study by the patient's physician who were selected through purposive sampling method. The sample size was calculated 21 subjects in each group (a total of 63 subjects) based on the formula and considered parameters, and also a standard deviation of 1.1 for pain intensity, as well as a relevant study and the least significant clinical difference in mean scores of outcome variables (score 2) and after also considering the attrition of $20 \%$ it became 75 subjects.

After obtaining approval from the University Ethics Committee, the written informed consent was obtained from the patients and they were divided into three groups using random block allocation $(25$ subjects per group).

Group A was subjected to the sole reflexology massage and group B received stretching exercises, whereas group C (control group) received routine interventions. Thus, both the group selection and the type of intervention were randomized.

Standardized visual analogue scale (VAS) was used to measure pain severity. This scale is a graded $10 \mathrm{~cm}$ line with a score of 10 indicating the worst pain and zero as no pain. Based on this scale, a score of 1-3 indicates mild pain, a score of 4-7 indicates moderate pain, and a score of 8-10 indicates severe pain.

Before the intervention, pain intensity was assessed using VAS by the researcher in all three groups. Interventions were performed for one month, three sessions per week (twelve 30-min sessions in total) in each group.

Sole reflexology massage was performed according to the protocol in three stages of preparation ( 5 $\mathrm{min})$, warming up (10 $\mathrm{min})$ and sole reflexology techniques (15 $\mathrm{min})$. To perform this intervention, one male and one female researcher were used for training male and female patients. The recovery point was started from the end of the first thumb strap and reached the heel [13]. Preparing and warming up of the legs was done by hand with certain movements, holding up and downside of the foot using both hands and making backward bending movements, bending the foot, turning outside and inside, and also some movements in the heels.

The stimulation of massage recovery points was performed by the hand fingers using sweep gestures with a pressure of about $0.5 \mathrm{~cm}$ [14]. Regarding reflexology massage, the patient was placed in a semi-seated position, with the head positioned 15 to 30 degrees above. Before massaging, the researcher removed his watch, ring, and bracelet and trimmed his thumb and forefinger nails.

Stretching exercises consisted of warming up for 10 min at first, then $15 \mathrm{~min}$ of the considered stretching exercises followed by $5 \mathrm{~min}$ of cooling. The stretching exercises were selected from a specialized source and designed so that they did not require any physical fitness and included only a simple warming-up.

Ten minutes after the last intervention, pain intensity was recorded again by the researcher 
using VAS. Patients in the control group received only routine treatments and care.

The collected data were analyzed by SPSS 21 software using descriptive and inferential statistics at a confidence level of 95\%. The data were analyzed by Kolmogorov-Smirnov test and after confirming normal distribution, one-way ANOVA and Tukey post hoc tests were used to compare mean pain intensity. Chi-square test was used to compare demographic variables between the groups.

\section{Findings}

Thirty-nine men and 36 women with a mean age of $44.6 \pm 10.0$ years (age range: 28-68 years) participated in the study. There was no significant difference between the groups in terms of sex, marital status, educational level, place of residence and occupation ( $\mathrm{p}>0.05$; Table 1$)$.

There was no statistically significant difference between the severity of pain in the three groups before the intervention $(p=0.1)$, but after the intervention, this difference was significant ( $p=0.001$; Table 2).

The observed difference was related to pain intensity in the stretching group patients with the control and sole reflexology massage groups $(\mathrm{p}<0.05)$. In other words, there was a significant decrease in pain intensity in the patients of the stretching group, but in the other two groups, there was no significant change in their pain intensity $(\mathrm{p}>0.05)$.

Table 1) Comparison of the absolute and relative frequency of demographic variables in the three study groups ( $\mathrm{n}=25$ in each group; numbers in parentheses are percentage)

\begin{tabular}{lccccc}
\multicolumn{1}{c}{ Variables } & Sole reflexology massage group & Stretching exercises group & Control group & Total & P. value \\
\hline Gender & & & & & \\
Male & $12(48.0)$ & $14(56.0)$ & $13(52.0)$ & $39(52.0)$ & 0.09 \\
Female & $13(52.0)$ & $11(44.0)$ & $12(48.0)$ & $36(48.0)$ & \\
Marital status & & & & $11(14.7)$ & 0.1 \\
Single & $3(12.0)$ & $6(24.0)$ & $2(8.0)$ & $64(85.3)$ & \\
Married & $22(88.0)$ & $19(76.0)$ & $23(92.0)$ & & \\
Education level & & & $7(28.0)$ & $19(25.3)$ & \\
Elementary & $2(8.0)$ & $9(36.0)$ & $5(20.0)$ & $13(17.3)$ & 0.38 \\
Secondary school & $4(16.0)$ & $4(16.0)$ & $10(40.0)$ & $31(41.3)$ & \\
High school & $14(56.0)$ & $8(32.0)$ & $3(12.0)$ & $12(16.0)$ \\
University & $5(20.0)$ & $4(16.0)$ & $20(80.0)$ & $57(76.0)$ \\
Place of residence & & & $5(20.0)$ & $18(24.0)$ & 0.1 \\
Urban & $18(72.0)$ & $19(76.0)$ & $2(8.0)$ & $4(5.3)$ \\
Rural & $7(28.0)$ & $6(24.0)$ & $6(24.0)$ & $18(24.0)$ \\
Occupation status & $1(4.0)$ & $1(4.0)$ & $5(20.0)$ & $18(24.0)$ \\
Manual worker & $7(28.0)$ & $5(20.0)$ & $5(20.0)$ & $12(16.0)$ & 0.1 \\
Employee & $5(20.0)$ & $8(32.0)$ & $6(24.0)$ & $20(26.7)$ \\
Non-governmental & $4(16.0)$ & $3(12.0)$ & $1(4.0)$ & $3(4.0)$ \\
Unemployed & $7(28.0)$ & $7(28.0)$ & & \\
Housewife & $1(4.0)$ & $1(4.0)$ & & \\
Student & & & & \\
\hline
\end{tabular}

Table 2) Inter-group comparison of the mean pain severity scores in the three studied groups before and after the intervention

\begin{tabular}{l|c|cccc}
\hline \multicolumn{1}{c}{ Table 2) Inter-group comparison of the mean pain severity scores in the three studied groups before and after the intervention } & \multicolumn{1}{c}{ Time } & Control group & Sole reflexology massage & Stretching exercises & F \\
\hline Before intervention & $5.5 \pm 2.7$ & $6.7 \pm 1.9$ & $6.4 \pm 2.3$ & 1.8 & 0.1 \\
After intervention & $5.6 \pm 2.7$ & $6.2 \pm 1.6$ & $4.3 \pm 2.0$ & 4.5 & 0.001 \\
\hline
\end{tabular}

\section{Discussion}

In the present study, the effect of sole reflexology massage and stretching exercises on pain intensity in patients with rheumatoid arthritis was compared. The results showed that the mean pain intensity in the sole reflexology massage group and stretching exercises group was different after the intervention. In other words, there was a significant difference in pain intensity in the sole reflexology massage and stretching exercises groups after the intervention, which was confirmed by the ANOVA test, so that stretching exercises reduced pain intensity in the studied subjects more than sole reflexology massage. It has shown that massage therapy can reduce pain in patients with fibromyalgia $[17,18]$ and stretching exercises have reduced the symptoms of patients with fibromyalgia and improved their lives
[19, 20]. The results of Amanollahi et al. study in 2012 comparing the effects of massage, stretching and drug therapy on pain relief in patients with fibromyalgia syndrome showed a significant difference in pain severity after intervention, which is consistent with the results of the present study, as the effect of stretching exercises on pain reduction was equal to drug therapy, but more than massage therapy [21].

Usually, all types of massage effect on the body by the same mechanism. When the muscle is overworked, the accumulation of wastes, including citric acid, can cause pain, cramps and even muscle spasms. Massage improves blood circulation and lymph flow, delivers fresh food and oxygen to the tissues and is helpful for removing toxins and healing. Stretching muscles can also put pressure on 
Comparison of the Effect of Sole Reflexology Massage and ... blood vessels and nerves and cause pain by restricting blood flow. Following massaging the affected area, muscle pressure on the involved nerves gradually decreases and pain is reduced [22,23].

Also, the intra-group comparison of mean pain intensity in stretching exercises group after the intervention compared to before intervention showed that stretching exercises had a significant effect on pain intensity in patients with rheumatoid arthritis. Williams et al. showed that doing exercise along with routine care was more effective and costeffective for patients with rheumatoid arthritis than using routine care alone [24]. Rahnam and Mazloom also showed that aerobic exercise programs can improve function and walking ability in patients with rheumatoid arthritis and strength training is more effective on the range of motion of the knee, and both aerobic and strength training reduce pain equally [25]. Dynamic exercise therapy has a positive effect on physical capacity [26] and can reduce disability and pain in patients by strengthening the muscles around the joint and reducing the pressure on it [27].

It should be noted that in this study, a questionnaire was used to assess pain reduction and the lack of objective methods are some of the limitations of the present study. Therefore, it is suggested to use both subjective and objective scales in future studies to evaluate the effectiveness of these rehabilitation techniques. Accordingly, not only the evaluation of the impact of the interventions is more actual, but collecting objective and subjective scales and assessing their relationship can provide more comprehensive and accurate information regarding the patients' problems.

According to the findings of the present study, although stretching exercises reduced the severity of pain in rheumatoid arthritis patients, however, further research is clinically needed to consider stretching exercises as a non-pharmacological measure in future studies.

\section{Conclusion}

Stretching exercises reduce the severity of pain in patients with rheumatoid arthritis, but sole reflexology massage does not improve and reduce pain in these patients.

Acknowledgments: This article was extracted from a Master's thesis in Nursing. We are grateful to the Yasuj University of Medical Sciences for funding the research and also the patients with rheumatoid arthritis who assisted us in conducting the study.

Ethical Permission: This study was approved by the Ethics Committee of Yasuj University of Medical Sciences.

Conflict of interests: There is no conflict of interests.

Authors' Contribution: Sadeghi M. (First author), Introduction author/ Original researcher/ Discussion author (30\%); Zabolipour S. (Second author), Introduction author/ Assistant/ Discussion author (12\%); Afrasiabifar A. (Third author), Methodologist/ Assistant/ Statistical
106

analyst/ Discussion author (28\%); Najafi Dolatabad S. (Fourth author), Introduction author/ Methodologist/ Original researcher/ Discussion author (30\%)

Funding: This research was funded by the Yasuj University of Medical Sciences.

\section{References}

1- Hegen M, Keith JC Jr, Collins M, Nickerson-Nutter CL. Utility of animal models for identification of potential therapeutics for rheumatoid arthritis. Ann Rheum Dis. 2008;67(11):1505-15.

2- Harrison TR, Braunwald E. Harrisos's principles of internal medicine: rheumatology \& immune system diseases. Abdollahi N, Abdollahi F, translators. Tehran, Teimourzadeh; 2017. [Persian]

3- Hill J, Hale C. Clinical skills: evidence-based nursing care of people with rheumatoid arthritis. $\mathrm{Br} \mathrm{J}$ Nurs. 2004;13(14):852-7.

4- Bliddal H, Danneskiold-Samsoe B. Chronic widespread pain in thespectrum of rheumatological diseases. Best Pract Res Clin Rheumatol. 2007;21(3):391-402.

5- Evers AW, Kraaimaat FW, van Riel PL, Bijlsma JW. Cognitive, behavioral and physiological reactivity to pain as a predictor of long-term pain in rheumatoid arthritis patients. Pain. 2001;93(2):139-46.

6- Fitzcharles MA, DaCosta D, Ware MA, Shir Y. Patient barriers to pain management may contribute to poor pain control in rheumatoid arthritis. J Pain. 2009;10(3):300-5.

7- Jakobsson U, Hallberg IR. Pain and quality of life among older people with rheumatoid arthritis and/or osteoarthritis: a literature review. J Clin Nurs. 2002;11(4):430-43.

8- Núñez M, Núñez E, Sanchez A, del Val JL, Bonet M, Roig D, et al. Patients' perceptions of health-related quality of life in rheumatoid arthritis. Clin Rheumatol. 2009;28(10):1157-65.

9- Strand EB, Zautra AJ, Thoresen M, Odegard S, Uhlig T, Finset A. Positive affect as a factor of resilience in the painnegative affect relationship in patients with rheumatoid arthritis. J Psychosom Res. 2006;60(5):477-84.

10- Black JM, Hawks JH, Keene AM. Medical surgical nursing. $6^{\text {th }}$ Edition. Philadelphia: WB Saunders; 2001.

11- Suomi R, Collier D. Effects of arthritis exercise programs on functional fitness and perceived activities of daily living measures in older adults with arthritis. Arch Phys Med Rehabil. 2003;84(11):1589-94.

12- Monjamed Z, Razavian F. The effect of symptoms and signs of disease on the quality of life of patients with rheumatoid arthritis referring to hospitals affiliated to Tehran University of Medical Sciences in 2005. J Qom Univ Med Sci. 2005;1(1):27-35. [Persian]

13- Salminen E, Heikkila S, Poussa T, Lagstrom H, Saario R, Salminen S. Female patients tend to alter their diet following the diagnosis of rheumatoid arthritis and breast cancer. Prev Med. 2002;34(5):529-35.

14- Lee YM, Sohng KY. The effects of foot reflexology on fatigue and insomnia in patients suffering from coal workers' pneumoconiosis. Taehan Kanho Hakhoe Chi. 2005;35(7):1221-8. [Korean]

15- Layzell M. Improving the management of postoperatve pain. Nurs Times. 2005;101(26): 34-6.

16- Abbasi Z, Abedian Z, Hasanpour Azghandi SB, Fadaei AR, Esmaili H. Study of the effects of massage therapy on the intensity of labor fatigue. J Sabzevar Univ Med Sci. 2007;14(3):172-8. [Persian] 
17- Kraft K, Kanter S, Janik H. T229 Reducing of pain in patients with fibromyalgia syndrome by applying a vibration massage device. Eur J Pain Suppl. 2011;5(1):44.

18- Field T, Diego M, Hernandez Reif M, Shea J. Hand arthritis pain is reduced by massage therapy. J Bodywork Move Ther. 2007;11(1):21-4.

19- Hoeger Bement MK, Weyer A, Hartley S, Drewek B, Harkins AL, Hunter SK. Pain perception after isometric exercise in women with fibromyalgia. Arch Phys Med Rehabil. 2011;92(1):89-95.

20- Busch AJ, Webber SC, Brachaniec M, Bidonde J, BelloHaas VD, Danyliw AD, et al. Exercise therapy for fibromyalgia. Curr Pain Headache Rep. 2011;15(5):35867.

21- Amanollahi A, Naghizadeh J, Khatibi A, Hollisaz MT, Shamsoddini A, Saburi A. Comparison of impacts of friction massage, stretching exercises and analgesics on pain relief in primary fibromyalgia syndrome: a randomized clinical trial. Tehran Univ Med J. 2013;70(10):616-22. [Persian]

22- Wiltshire EV, Poitras V, Pak M, Hong T, Rayner J, Tschakovsky ME. Massage impairs postexercise muscle blood flow and "lactic acid" removal. Med Sci Sports Exerc.
2010;42(6):1062-71.

Sadeghi et al.

23- Ekici G, Bakar Y, Akbayrak T, Yuksel I. Comparison of manual lymph drainage therapy and connective tissue massage in women with fibromyalgia: a randomized controlled trial. J Manipulative PhysiolTher. 2009;32(2):127-33.

24- Williams MA, Williamson EM, Heine PJ, Nichols V, Glover MJ, Dritsaki M, et al. Strengthening and stretching for Rheumatoid Arthritis of the Hand (SARAH). A randomised controlled trial and economic evaluation. Health Technol Assess. 2015;19(19):1-222.

25- Rahnama N, Mazloum V. Effects of strengthening and aerobic exercises on pain severity and function in patients with knee rheumatoid arthritis. Int J Prev Med. 2012;3(7):493-8.

26- Van den Ende CH, Vliet Vlieland TP, Munneke M, Hazes JM. Dynamic exercise therapy in rheumatoid arthritis: a systematic review. Br J Rheumatol. 1998;37(6):677-87.

27- Behboodi M, Atashzadeh Shoorideh F, Noorian M, Jambarsang S, Mohtashami G. The effect of aerobic exercise (stretching exercise) on the fatigue severity of nurses in NICU. J Nurs Midwifery Urmia Univ Fac. 2015;12(12):1110-8. [Persian] 